\title{
"It's just a ding, Coach; I can play"—But should he?
}

\author{
Janet Jankowiak, MD; and Elizabeth Roaf, MD
}

Fall starts the season for football, soccer, and rugby, followed by ice hockey and skiing - a time when head injuries may occur. "Mild" head injuries, also known as concussions, are common with these and other sports, as well as other situations in which falls occur (see below: "About Concussion"). When an athlete gets a concussion, a key question asked by parents, coaches, and medical personnel is, "When can he/she safely return to play?" Frequently, athletes return to play immediately after the injury without realizing that this may be a serious mistake. Neurologists have known for some time that a second concussion within days or weeks of a first can have catastrophic consequences. It is as if a second paper cut in a week could cause someone to bleed to death. Mindful of the dangers of this "second impact syndrome," the American Academy of Neurology issued "Return to Play" guidelines. ${ }^{1}$

New research, reported in this issue of Neurology, suggests that athletes with repeated concussions are more likely to have ongoing problems from their injury than those with a first-time concussion. Bruce et al. ${ }^{2}$ studied college athletes, playing a variety of sports, to understand the impact that one or more concussions may have in terms of long-term symptoms. A questionnaire was given to 433 male athletes at the beginning of the study to determine whether they had ever had a concussion and whether they had any current symptoms of concussion. During the study period, 57 athletes sustained concussions. Of these 57 athletes, 30 had a history of a previous concussion and the other 27 had not had a previous head injury. Each injured athlete was given a 21item test designed to look at memory, attention, and emotional factors (known as neuropsychological testing) as well as physical symptoms of con- cussion. These tests were given 2 hours after injury, 48 hours after injury, and 1 week after injury. Twenty-nine other athletes who had no concussion during the study period and for at least 6 months before the study (known as the control group) were given the same 21-item test for comparison.

At the start of the study, athletes with a history of a concussion before the study reported more concussive symptoms than athletes who had never had a concussion. As expected, athletes with a new concussion, with or without previous history of concussion, reported more symptoms than control athletes (those with no history of head injury for at least 6 months) at 2 hours and 48 hours after the concussion. However, at 2 hours after the new concussion, those with a history of a previous concussion were less likely to report symptoms than those who sustained their first concussion. There was no difference between these two groups reporting at 48hour testing. At 1 week, those athletes with a recent concussion and a previous concussion were four times more likely to report at least one problem with balance/thinking than those with only a recent concussion. Eight percent of those who had sustained a first concussion reported difficulty with balance or thinking, while nearly a third (32\%) of those with more than one concussion reported these symptoms 1 week after the injury. This suggests that a second concussion may take longer to heal than the first one.

Surprisingly, immediately after the injury, those with a previous history of concussion reported fewer symptoms than those experiencing their first concussion. At 1 week after injury, however, they reported more symptoms. The authors believe that those with repeat concussions were, consciously or unconsciously, underreporting their symptoms at 2 hours, perhaps trying to minimize their symptoms in order to return to play. These athletes might be more familiar with their symptoms and aware that they might need to stay on the sideline longer with a history of prior concussion. In any case, this finding is consistent with research that shows that many head-injured patients lack "insight" into their injuries. That is, they don't realize how badly hurt they are and how their thinking has been impaired. "It was only a ding, Coach. I can play!"

The authors concluded that athletes with a previous history of concussion appear to have symptoms for a longer period of time. From this research, coaches, parents, and medical personnel should take home the following message:

- Carefully follow the AAN's guidelines for sideline evaluation of head injury and return-to-play times. $^{1}$

- Return-to-play criteria should look at total concussion history, not just the concussions that occur within the same season.

- Never rely on the athlete's own evaluation of the severity of a head injury and his/her ability to return to play.

- Treat repeat concussions as potentially serious, with thorough medical evaluation, neuropsychological testing, and extended healing time.

\section{References}

1. American Academy of Neurology Quality Standards Subcommittee. Practice parameter: the management of concussion in sports (summary statement). Neurology 1998;48: 581-585. Available at: http://aan.com/professionals/practice/pdfs/pdf_1995_thru_1998/ 1997.48.581.pdf. Accessed August 30, 2004.

2. Bruce JM, Echemendia RJ. Concussion history predicts self-reported symptoms before and following a concussive event. Neurology 2004;63:1516-1518. 


\section{What is a concussion?}

A concussion is a change in the way the brain functions that results from an injury to the head. Loss of consciousness may occur, but not always. Confusion and problems with memory are key features of concussion. This confusion may occur immediately after a blow to the head or several minutes later. Therefore, the injured person must be watched very closely for some time to be sure that he/she does not become confused or develop a memory problem. It is also important to learn whether the victim has had any recent or distant head injury, such as a motor vehicle accident, because this may seriously worsen the situation.

\section{What are the signs of concussion?}

- Blank stare

- Slow to answer questions or follow instructions

- Easily distracted and unable to follow through with normal activities

- Disoriented: walking in the wrong direction; unaware of time, date, and place

- Slurred speech or not making sense when talking

- Stumbling, unable to walk on a straight line

- Overly emotional: distraught, crying for no apparent reason

- Memory problem: may repeatedly ask the same question; unable to memorize and recall 3 words or 3 of 3 objects in 5 minutes (sideline test)

- Any period of loss of consciousness: unresponsive to arousal

\section{What are complaints of concussion?}

Within the first minutes to hours after the injury, the head-injured person may complain of:
- Headache

- Dizziness or spinning

- Nausea or vomiting

- Lack of awareness of surroundings

Days to weeks after the injury, other problems may emerge:

- Nagging, low-grade headache

- Light-headedness

- Poor attention and concentration

- Irritability and low tolerance for frustration

- Problems with memory, especially for recent events

- Easily tired

- Problems sleeping

- Intolerance of loud noises, sometimes ringing in the ears

- Intolerance of bright lights or difficulty focusing vision

- Anxiety or depressed mood

\section{Problems with insight \& judgment}

Perhaps one the most frustrating features of head injury is an apparent lack of insight and judgment. The head-injured victim tends to ignore or downplay the severity of the injury or the lingering problems. Poor judgment or denial leads him/her to insist on returning to prior activities possibly too early. This may set up a vicious cycle for repeated injury.

\section{Prevention is the best defense} Although it is critical to recognize a concussion when it does occur and not rush back into activity, preventing head injury is even better. In contact sports, it is clear that protective equipment should be used properly. However, there are many other situations in which head injury could be avoided or reduced by thinking ahead. Avoiding "risky behaviors," including acts of violence, is as important as wearing proper headgear. Many "accidents" can be avoided by being aware and responding to possi- bly dangerous conditions or situations:

- Wear helmets for cycling, skateboarding, roller blading, skiing, snowboarding, riding all-terrain vehicles, snowmobiles, or scooters, and for other sports with a high risk of falls or crashes. Correct positioning of the helmet is critical: it should cover the forehead just above the eyebrows, with the strap tight enough that the helmet does not tip if hit (see photo). Use a helmet specific to the sport.

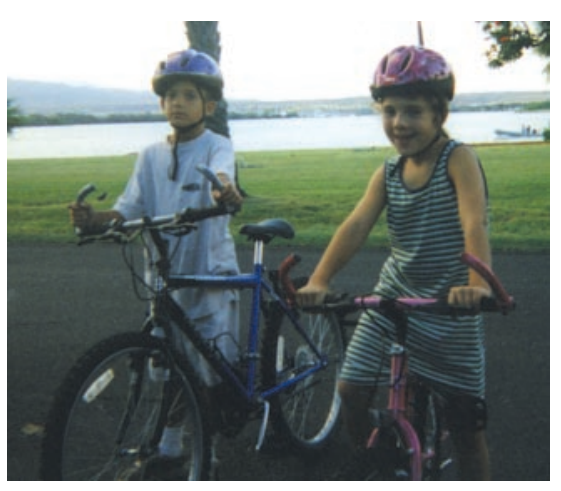

- Wear seat belts when driving, even for very short distances.

- Avoid drugs and excessive drinking, especially with driving.

- If you are excessively tired or angry, avoid driving.

- Solve disagreements with words, not violence.

- Use your head to think, not to hit a ball or anything else deliberately: The Brain Matters!

\section{For more information}

American Academy of Neurology Foundation www.thebrainmatters.org Brain Injury Association www.biausa.org 


\title{
Neurology
}

\author{
"It's just a ding, Coach; I can play"--But should he? \\ Janet Jankowiak and Elizabeth Roaf \\ Neurology 2004;63;E15 \\ DOI 10.1212/01.WNL.0000144836.35899.8C
}

This information is current as of October 25, 2004

\section{Updated Information \& Services}

References

Permissions \& Licensing

Reprints including high resolution figures, can be found at: http://n.neurology.org/content/63/8/E15.full

This article cites 1 articles, 1 of which you can access for free at: http://n.neurology.org/content/63/8/E15.full\#ref-list-1

Information about reproducing this article in parts (figures,tables) or in its entirety can be found online at:

http://www.neurology.org/about/about_the_journal\#permissions

Information about ordering reprints can be found online: http://n.neurology.org/subscribers/advertise

Neurology ${ }^{\circledR}$ is the official journal of the American Academy of Neurology. Published continuously since 1951, it is now a weekly with 48 issues per year. Copyright. All rights reserved. Print ISSN: 0028-3878. Online ISSN: 1526-632X.

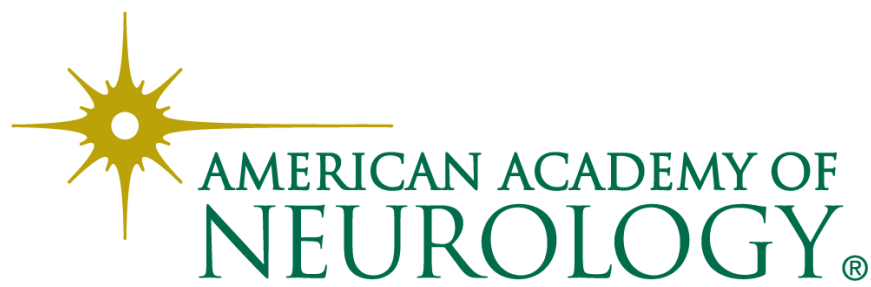

